\title{
Life Expectancy of Polymeric Hollow Fibre Heat Transfer Surfaces
}

\author{
Tereza Brozova, Tereza Kroulikova \\ Heat Transfer and Fluid Flow Laboratory/Brno University of Technology \\ Technicka 2896/2, 61669 Brno, Czech Republic \\ Tereza.Brozova@vut.cz; Tereza.Kroulikova@vut.cz
}

\begin{abstract}
This article deals with polymer hollow fibre heat exchangers as an alternative to the common metal heat exchangers. These heat exchangers are made of hundreds or even thousands of polymer hollow fibres. The heat exchangers provide such benefits as low weight, corrosion resistance, and easy shaping and machining. Moreover, they are environmentally friendly. These fibres are the key part of such heat exchangers. Therefore, it is necessary to ensure their durability during their lifetime. The paper shows tests the life expectancy of hollow fibres by internal pressure loading. The tests are performed in a water bath at a temperature of $80^{\circ} \mathrm{C}$. This simulates the operating conditions of the heat exchangers.
\end{abstract}

Keywords: Hollow fibre, Heat exchanger, Heat transfer, Polymeric hollow fibre heat exchanger, Fatigue.

\section{Introduction}

The commonly used metal heat exchangers are not sufficient for all applications. One of their main disadvantages is corrosion. Nowadays, the polymeric heat exchangers are used in the applications when it is necessary. Their key disadvantage is their low thermal conductivity, which is between $0.1 \mathrm{Wm}^{-1} \mathrm{~K}^{-1}$ and $0.4 \mathrm{Wm}^{-1} \mathrm{~K}^{-1}[1]$.

Polymeric hollow fibre heat exchangers are a new alternative to polymeric heat exchangers. The first mention of them was made approximately 15 years ago [2]. They consist of hundreds of polymer hollow fibres. The outer diameter of these fibres is around $1 \mathrm{~mm}$ and the wall thickness is approximately $10 \%$ of the outer diameter. It can be more depending on the requirements for the application. These heat exchangers have such advantages as low weight, corrosion resistance, and easy shaping and machining. Moreover, the energy required to produce a unit of mass of polymers is much lower than for the same amount of metal. Therefore, they are environmentally friendly. Moreover, they are recyclable. [3], [4]

The main disadvantage of polymeric hollow fibre heat exchangers is the limits to their operating temperature. Hence, these heat exchangers are appropriate for use in low temperature applications in HVAC. For example, polypropylene heat exchangers can be operated up to $90^{\circ} \mathrm{C}$. However, heat exchangers made of polyether ether ketone can be operated up to $200^{\circ} \mathrm{C}$. The possibility to use them in electronic systems is described in [5]. The study of their use in heat transfer processes when condensation occurs is in [6]. The condensation on a surface is significantly influenced by its wettability. The wettability of polymeric hollow fibres was studied in [7].

Another possible use of polymeric hollow fibre is as a membrane. These membranes have the same advantages as polymer hollow fibre heat exchangers and can be used for example in filtration processes, chemical separation or for medical treatment. [8], [9], [10]

\section{Experimental Section}

The paper deals with the testing of polymer hollow fibres by pressure loading. The aim of the test is to prove the suitability of these fibres for polymer hollow fibre heat exchangers. The operating conditions are simulated during the test. The samples are placed in a hot water bath at $80^{\circ} \mathrm{C}$. Meanwhile, the pressure inside the fibres is rapidly increasing and decreasing. The testing is based on ISO 19892:2011(E) [11] which determines the test method for resistance plastic piping systems for hot and cold water. According to the international standard [11] the samples should achieve 10000 successful cycles to pass the test. 


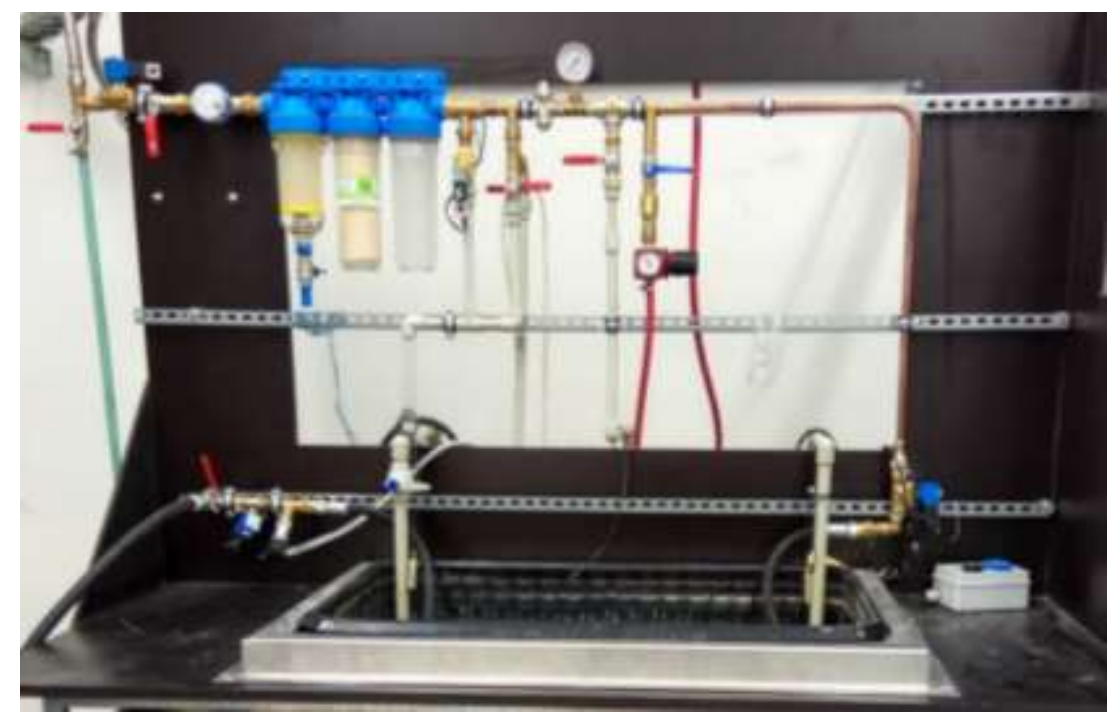

Fig. 1: The test rig serving for the fatigue testing.

The tests were performed by using the test rig that is shown in Fig. 1. On the top is the water supply with the three-stage water filtration. The container at the bottom serves as a water bath, which can simulate the temperature. Its scheme is in Fig. 2. The water supply starts rom the electromagnetic valve (1) that serves as a safety valve, which shuts down the water supply in case of failure. The valve (2), water meter (3), and three-stage water filtration (4) follow. The electromagnetic valve (5) is connected to the system that controls the water level in the bath. The reduction valve (6) is used when the samples are tested up to 4 bar and the pressure is observed by the manometer (7). The position of the three-way valve (8) then determines the flow inside the pipes. When the samples are tested by the pressure 4-15bar the pump (15) is used to pump water in the expansion vessel (17). The pump is controlled by the pressure switch (18). The safety valve (16) is between the pump and the expansion vessel. The pressure of the testing water is displayed on the manometer (19). The electromagnetic valves (9) and (10) are controlled by the computer for testing itself. The tested samples are represented by (11). The pressure is measured at the sample output by the pressure probe (12) with an error $\pm 0.35 \%$ (which gives a maximal error of 0.04 bar). The heater (13) is used to obtain the required temperature of the water bath. The temperature of the bath is measured by the temperature probe Pt100 (14) with an accuracy of $1 / 3$ DIN that gives an error $\pm 0.24^{\circ} \mathrm{C}$. The presence of defects is detected by the pressurising of the samples by the air from the inside and observing the bubbles in the water bath. The air comes through the reduction valve (20) and the pressure is displayed by the manometer (21). The valve (22) follows. The test itself can be described as the sequence of the following steps:

1. After running the test, the electromagnetic valve (1) is opened.

2. The electromagnetic valves (9) and (10) are closed (the pressure inside the sample is zero).

3. The input electromagnetic valve (9) is opened and the sample is pressurised.

4. The input electromagnetic valve (9) is closed - the sample is left for a defined time at the pressure level.

5. The output electromagnetic valve (10) is opened and the pressure is released.

6. The output electromagnetic valve (10) is closed.

7. Return to step 3.

The test runs until the defect's presence is controlled by the pressurised air, until it fails or until the test is successful. The test rig is automatically disconnected from the electricity and water when the failure is detected. 


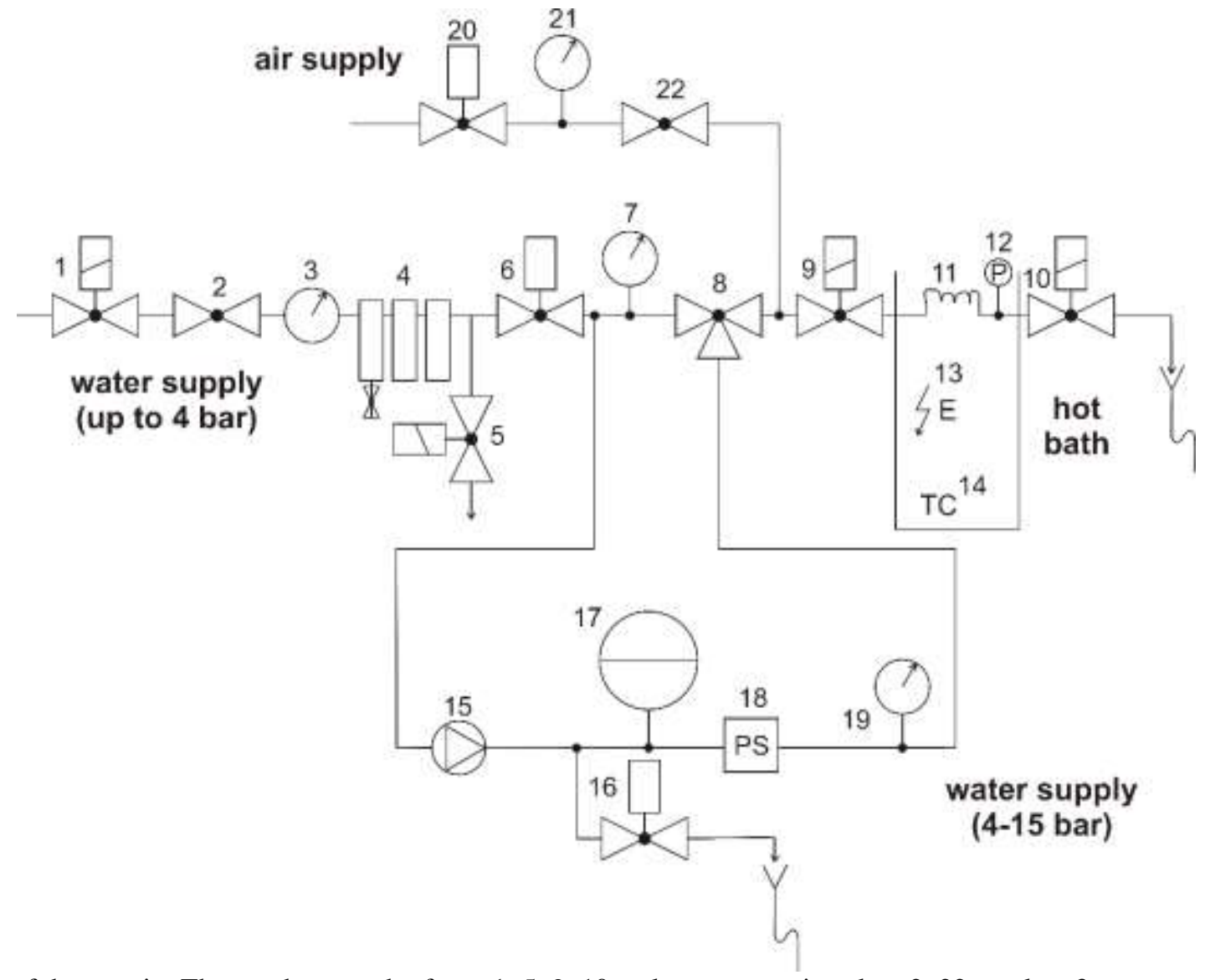

Fig. 2: Scheme of the test rig. The numbers used refer to 1, 5, 9, 10 - electromagnetic valve; 2,22 - valve; 3 - water meter; 4 - threestage water filtration; 6, 20 - reduction valve; 7, 19, 21 - manometer; 8 - three-way valve; 11 - tested sample; 12 - pressure meter; 13 - heater; 14 - temperature meter (Pt100); 15 - pump; 16 - safety valve; 17 - expansion vessel; 18 - pressure switch.

Six samples were tested. Three samples were made of polypropylene and three of polyamide. The number of samples is in agreement with the standard [11]. The samples were extruded on different days so the test would be repeatable of. Each sample is made of $5 \mathrm{~m}$ of fibre which is rolled into a tangle for better handling and immersed in a water bath. The installed samples before testing are shown in Fig. 3. The testing conditions were set at 10bar inner pressure and the water bath was $80^{\circ} \mathrm{C}$. 


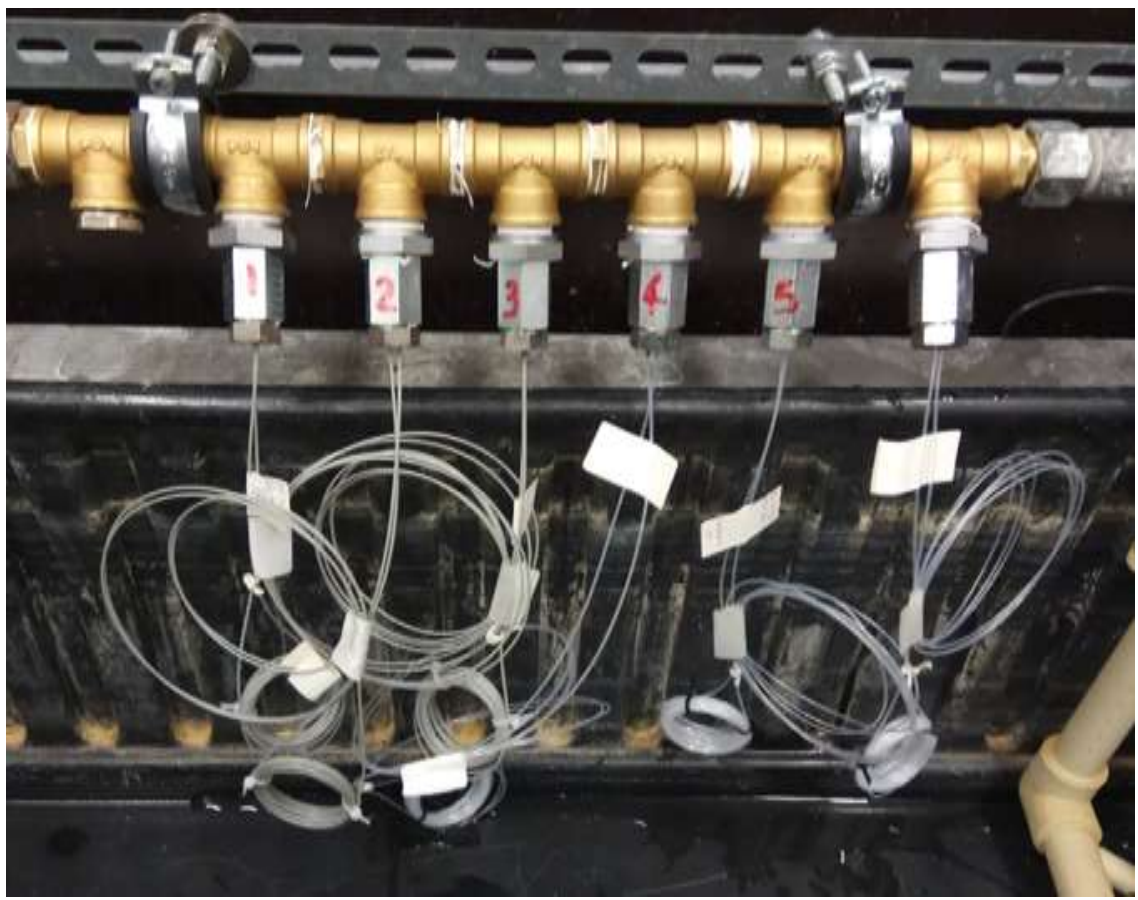

Fig. 3: The studied samples before testing.

\section{Results and Discussion}

The testing inner pressure was set as 10bar. The pressure varies slightly due to the use of the expansion vessel. Therefore, a slightly higher pressure was used to guarantee the pressure will never be lower than 10bar. The typical pressure profile during the testing is shown in Fig. 4.

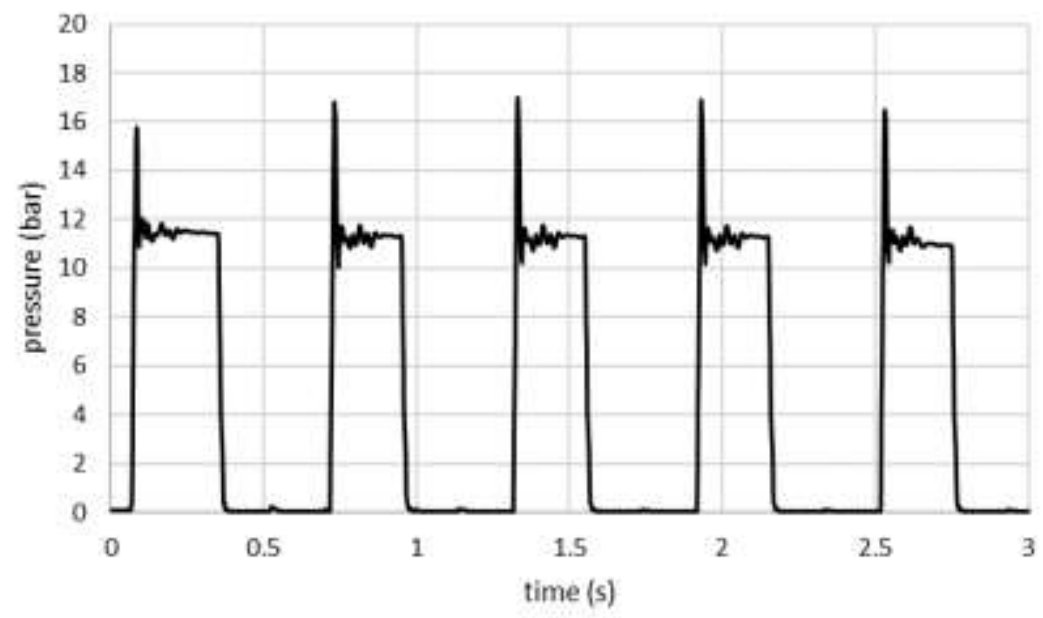

Fig. 4: The pressure profile during the testing.

The test ran automatically with few pauses for seeking the presence of the defect by using the pressurised air. No defect was detected. The samples reached one million successful pressure cycles. That is 100 times more than is defined by the standard ISO 19892:2011(E). 
A burst pressure test was also performed for these fibres in the $80^{\circ} \mathrm{C}$ water bath. The burst pressure test for the polypropylene fibre in the $80^{\circ} \mathrm{C}$ water bath is 47.5 bar. The typical defect is shown in Fig. 5 . For the polyamide fibre in the the same conditions the burst pressure is $48.4 \mathrm{bar}$.

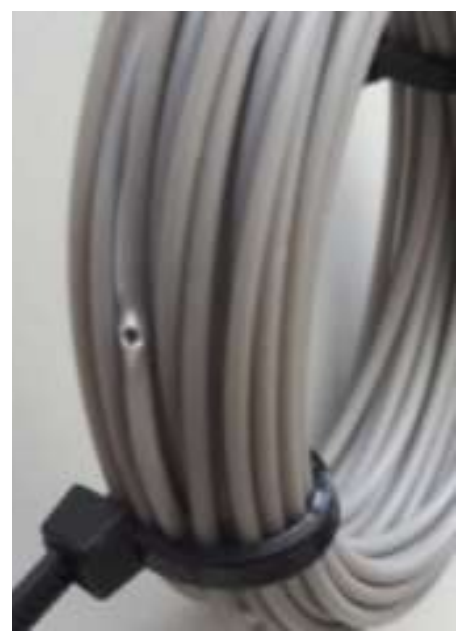

Fig. 5: The defect after burst pressure test, conditions were $80^{\circ} \mathrm{C}$ water bath and $48 \mathrm{bar}$.

\section{Conclusions}

The tested samples were selected with regard to the repeatability of the test i.e. each fibre was produced on a different day to avoid systematic errors. The sample consists of $5 \mathrm{~m}$ of fibre, which also provides a representative sample.

The testing conditions were chosen as $10 \mathrm{bar}$ inner pressure and a water bath of $80^{\circ} \mathrm{C}$. They were selected with regard to the operating conditions for which the heat exchangers are designed.

All samples were tested in agreement with ISO 19892:2011(E). The standard requires 10000 successful cycles to pass the test. However, the samples studied reached one million cycles, which is 100 times more than it is necessary. After one million successful cycles the test was terminated.

The burst pressure of the polypropylene fibre in the $80^{\circ} \mathrm{C}$ water bath is 47.5 bar and for the polyamide fibre $48.4 \mathrm{bar}$.

The study proves the suitability of polypropylene and polyamide hollow fibre for polymeric hollow fibre heat exchangers.

\section{Acknowledgements}

This work was suported by the Ministry of Education, Youth and Sports of the Czech Republic under OP RDE grant number CZ.02.1.01/0.0/0.0/16_019/0000753 "Research centre for low-carbon energy technologies".

\section{References}

[1] K. Weiß, I. Astrouski, M. Reppich and M. Raudensky, "Polymeric Hollow-Fiber Bundles as Immersed Heat Exchangers," Chem. Eng. Technol., vol. 41, no. 7, pp. 1457-1465, 2018.

[2] D. M. Zarkadas, K. K. Sirkar, "Polymeric hollow fiber heat exchangers: an alternative for lower temperature applications," Ind. Eng. Chem. Res., vol. 43, no. 25, pp. 8093-8106, 2004.

[3] M. Schmidt, I. Astrouski, M. Reppich and M. Raudensky, "Solar panel cooling system with hollow fibres," Appl. Sol. Energ., vol. 52, no. 2, pp. 86-92, 2016.

[4] J. Hejcik, P. Charvat, L. Klimeš and I. Astrouski, "A PCM-water heat exchanger with polymeric hollow fibres for latent heat thermal energy storage: a parametric study of discharging stage," J. Theor. App. Mech.-Pol., vol. 54, no. 4, pp. 1285-1295, 2016. 
[5] M. Raudensky, I. Astrouski, T. Brozova and E. Bartuli, "Flexible polymeric hollow fiber heat exchangers for electronic systems," in 2016 15th IEEE Intersociety Conference on Thermal and Thermomechanical Phenomena in Electronic Systems, Las Vegas, NV, pp. 1143-1147, 2016.

[6] T. Brozova, E. Bartuli, "Influence of Condensation on the Outer Surface of Polymer Hollow Fiber Heat Exchangers during Heat Transfer," in ASME 2018 16th International Conference on Nanochannels, Microchannels, and Minichannels. Dobrovnik, HR, pp. 1-6, 2018.

[7] T. Brozova and M. Raudensky, "Determination of surface wettability of polymeric hollow fibres," J. Elastomers Plast., vol. 50, no. 8, pp. 737-746, 2018.

[8] P. Bulejko, M. Dohnal, J. Pospisil, et al., "Air filtration performance of symmetric polypropylene hollow-fibre membranes for nanoparticle removal," Sep. Purif. Technol., vol. 197, pp. 122-128, 2018.

[9] T. Sverak, P. Bulejko, J. Ostrezi, et al., "Separation of gaseous air pollutants using membrane contactors," in Proceedings of 1st International Conference on Advances in Environmental Engineering, Ostrava, CZ, 2017, vol. 92, pp. 1-6.

[10] P. Bulejko, V. Adamec, R. Skeřil, B. Schüllerová and V. Bencko. "Levels and Health Risk Assessment of PM 10 Aerosol in Brno, Czech Republic," Cent. Eur. J. Public Health, vol. 25, no. 2, pp. 129-134, 2017.

[11] ISO 19892:2011(E). Plastic piping systems - Thermoplastics pipes and fittings for hot and cold water - Test methods for the resistance of joints to pressure cycling. Switzerland: ISO, 2011. 